\title{
Asymmetric Relationship Between Mid-latitude Eurasian Circulation and Summer Rainfall in Hong Kong in Different Phases of ENSO
}

\begin{abstract}
Yana $\mathrm{Li}^{1 \dagger}$, Ho-Nam Cheung ${ }^{2,3 *}$ and Wen $\mathrm{Zhou}^{4}$
${ }^{1}$ Institute of Environment, Energy and Sustainability, The Chinese University of Hong Kong, Hong Kong, China, ${ }^{2}$ School of Atmospheric Sciences and Guangdong Province Key Laboratory for Climate Change and Natural Disaster Studies, Sun Yat-sen University, Zhuhai, China, ${ }^{3}$ Southern Marine Science and Engineering Guangdong Laboratory (Zhuhai), Zhuhai, China, ${ }^{4}$ Center for Ocean Research in Hong Kong and Macau (CORE), School of Energy and Environment, City University of Hong Kong, Hong Kong, China
\end{abstract}

OPEN ACCESS

Edited by:

Lin Wang,

Institute of Atmospheric Physics (CAS), China

Reviewed by:

Juan Feng,

Institute of Atmospheric Physics

(CAS), China

Boqi Liu,

Chinese Academy of Meteorological Sciences, China

*Correspondence:

Ho-Nam Cheung

zhanghlan5@mail.sysu.edu.cn

${ }^{\dagger}$ Present Address:

School of Energy and Environment,

City University of Hong Kong, Hong Kong, China

Specialty section:

This article was submitted to

Atmospheric Science,

a section of the journal

Frontiers in Earth Science

Received: 16 December 2020

Accepted: 18 January 2021

Published: 19 February 2021

Citation:

Li Y, Cheung H-N and Zhou W (2021)

Asymmetric Relationship Between

Mid-latitude Eurasian Circulation and

Summer Rainfall in Hong Kong in

Different Phases of ENSO.

Front. Earth Sci. 9:642588.

doi: 10.3389/feart.2021.642588
During the period 1979-2019, the interannual variation of summer rainfall in Hong Kong $(\mathrm{HK})$, located on the South China coast, is weakly correlated with tropical forcing, including the El Niño/Southern Oscillation (ENSO). Instead, HK summer rainfall is strongly correlated with the mid-latitude circulation over the Urals and the preceding spring sea surface temperature (SST) over the North Atlantic (SST-Atl). The above relationship is stronger in negative ENSO summers, where the SST-Atl anomaly tends to persist from spring to summer. The persistence of the warm SST-Atl anomaly is associated with a Rossby wave train propagating from the North Atlantic to East Asia, with a low over the Urals and a high over the high latitudes of Asia. Correspondingly, the upper-tropospheric westerly jet in East Asia becomes stronger and shifts southward toward South China. The enhanced westerly wind over South China is accompanied by an anomalous Philippine Sea anticyclone, which transports more water vapor to the South China coast and causes more rainfall in HK. On the other hand, during positive ENSO summers, HK summer rainfall is affected by variation in the subtropical westerly jet over South China, which is related to water vapor transport from the Indian Ocean and Bay of Bengal. This is also associated with a height anomaly over northeastern China and the spring sub-polar North Atlantic SST. Therefore, it is important to investigate the impact of mid-latitude forcing on summer rainfall on the South China coast.

\footnotetext{
Keywords: Hong Kong rainfall, summer climate anomaly in China, spring North Atlantic SST, Ural high, extratropical wave train
}

\section{INTRODUCTION}

Hong Kong (HK) is a subtropical city with hot and humid weather in the boreal summer and cold and dry weather in the boreal winter. These characteristics are related to a seasonal reversal of wind direction associated with the East Asian monsoon, which arises from the land-sea thermal contrast and the topographic forcing exerted by the Tibetan Plateau (He et al., 1987; Tao and Chen, 1987; Wu et al., 2013). In HK, a coastal city adjacent to the South China Sea (SCS), summer rainfall is affected by tropical cyclone activity and the SCS summer monsoon (SCSSM), which marks the beginning of the rainy season. Li et al. (2015) showed that tropical cyclones account for around $20-25 \%$ of the 
rainfall in HK from July to October, and the percentage increases to about $40 \%$ for heavy rainfall (daily rainfall $>100 \mathrm{~mm}$ ). South China, including HK, usually has more (less) rainfall during a strong (weak) SCSSM, which is likely preceded by an early (late) SCSSM onset (Zhou et al., 2005).

During the past few decades, the intensity of the SCSSM and the tropical cyclone activity over the western North Pacific have had strong interannual and interdecadal variation (Chan and Zhou, 2005; Kajikawa and Wang, 2012; Yuan, et al., 2012; Chen et al., 2013; Wang, et al., 2012; Li, et al., 2014; Li and Zhou, 2014; Liu and Chan, 2019). Concomitantly, summer rainfall in HK has had considerable interannual and interdecadal variation (Leung et al., 2004). Because HK is a densely populated city, seasonal forecasts of summer precipitation several months ahead are useful for government and policy makers to minimize loss due to flooding caused by extreme precipitation events. A strong and advanced SCSSM is usually linked to anomalous warming over the SCS and western tropical Pacific in spring (Zhu and Li, 2017; Li et al., 2019b). The El Niño-Southern Oscillation (ENSO, also known as El Niño and La Niña) is one of the most predictable phenomena over the tropical Pacific on interannual timescales, so it might be regarded as a potential predictor of the summer upper-tropospheric circulation in the Northern Hemisphere (Lee et al., 2011) and the summer rainfall in South China (Chan and Shi, 1999; Jiang and Zhu, 2021). Based on technical reports from the Hong Kong Observatory (HKO), ENSO and the intensity of the East Asian winter monsoon in the preceding winter are two important predictors of annual rainfall in HK (Chang and Yeung, 2003). A strong El Niño developing year (e.g., 1982 and 1997) tends to be wet, and a year following a strong La Niña onset (e.g., 1984 and 1999) tends to be dry. However, Zhou and Chan (2007) pinpointed that the SCSSM tends to have an early (late) onset and bring South China more (less) rainfall during a cold (warm) ENSO event. In general, El Niño does not have a significant impact on East Asian summer precipitation (Wang et al., 2017). The ENSO could better explain the autumn rainfall in South China (Wu et al., 2003). Compared to ENSO, other tropical forcing, such as sea surface temperature (SST) over the tropical central Pacific and a dipole sea surface temperature tendency in the Indo-Pacific warm pool in the previous winter, are more closely related to early summer rainfall over South China (He and Wu, 2014; Yim et al., 2014; Xing et al., 2016). We will show that the interannual variation of $\mathrm{HK}$ summer rainfall is not significantly correlated with tropical forcing.

The internal dynamics of the East Asian summer monsoon involves the tropical-midlatitude interactions (Tao and Chen, 1987; Lau et al., 2000). The summer rainfall over South China is also modulated by mid-latitude forcing other than tropical forcing. Following a weak winter monsoon, persistent cyclonic anomalies over the South China coast can enhance the East Asian summer monsoon (Chen et al., 2000; Wu and Chan, 2005; Chen et al., 2013). Prior to the SCSSM onset, frequent intrusion of synoptic disturbances from the midlatitudes into South China can trigger vigorous frontal precipitation and facilitate the SCSSM onset (Wang, 1992; Wang and Yasunari, 1994; Ding and Li, 1999; Ding and Chan, 2005; Zheng et al., 2006; Lin et al., 2010). The frontal precipitation over South China is related to the local lower-tropospheric meridional temperature gradient (Huang and Chen 2015). After the SCSSM onset, monsoonal fronts usually form at interfaces of tropical and extratropical forcing to bring frontal rainfall over South China. Such extratropical forcing is strongly modulated by blocking highs (Ninomiya and Shibagaki, 2007; Wu et al., 2009; Yim et al., 2014). The co-existence of blocking highs over the Ural Mountains and the Sea of Okhotsk, as well as a deep trough between the highs, can trigger persistent and intense subtropical frontal precipitation over East Asia (Ding and Chan, 2005; Chen and Zhai, 2014). A pronounced winter warming tendency from December to February over Siberia is associated with reduced snow cover over eastern Siberia in the subsequent summer, which favors warming and the occurrence of blocking highs over the Sea of Okhotsk, leading to increasing summer rainfall over South China (Yim et al., 2014).

On the other hand, Gong and Ho (2003) showed that the positive phase of the late spring Arctic Oscillation is related to a northward shift in the upper-tropospheric jet over East Asia in summer. This accompanies anomalous sinking motion over subtropical East Asia, which corresponds to less rainfall along the Meiyu-Baiu-Changma region and more rainfall in South China. Such an opposite precipitation anomaly is also be linked to the southeast-northwest movement of the South Asian high (Wei et al., 2015) and the meridional displacement of the subtropical jet stream over East Asia (Kim and Ha, 2021). Recently, Dai et al. (2020) proposed that a wave train propagating from Russia to China via the Tibetan Plateau affects the rain belts over Southeast China. Lin (2014) showed that the positive phase of the East Atlantic/Western Russia teleconnection pattern is accompanied by a southeastward propagation of a Rossby wave train over East Asia. This is related to a significant negative height anomaly and more rainfall over South China. We will show that the midlatitude forcing could strongly modulate HK summer rainfall.

The interannual variation of the East Asian summer monsoon is also linked to the pre-season sea surface temperature (SST) and the large-scale atmospheric circulation over the North Atlantic. Sung et al. (2006) found that the positive phase of the North Atlantic Oscillation (NAO), which is the dominant mode of the North Atlantic atmospheric circulation, in the preceding December could induce a northward shift in the westerly jet over East Asia in June and suppress summer rainfall in South China. Such a delayed impact is dynamically bridged by a Eurasian wave train trapped in the westerly waveguide, where the wave train is excited by anomalous upper-level convergence over the Mediterranean Sea after February (Watanabe, 2004). Moreover, following a positive winter NAO, the summer $500-\mathrm{hPa}$ geopotential height anomaly over the Sea of Okhotsk tends to be positive (Ogi et al., 2004), which could affect summer rainfall over South China.

The spring NAO is also correlated with the East Asian summer monsoon, where the spring NAO influences the North Atlantic tripolar SST anomaly and the subsequent Rossby wave train response over Eurasia (Wu et al., 2009; Yim et al., 2014; Li et al., 2019a). The summer NAO or the North Atlantic tripolar SST can excite a wave train over Eurasia continent and influences 
diabatic heating over the Tibetan Plateau, which triggers a subtropical wave train. The midlatitude and subtropical wave trains jointly affect the extreme weather events in East Asia, such as the heatwave over northeastern China in 2018 and the extreme Meiyu season in 2020 (Wang et al., 2018; Liu et al., 2019; Liu et al., 2020). Chen et al. (2017) found that the interannual variation of NAO has a stronger relationship with the summer rainfall in south China after early 1990s. On interdecadal timescales, Chan and Zhou (2005) demonstrated that early summer monsoon rainfall over South China tends to be below or above normal when ENSO and the Pacific decadal oscillation are in phase. The Atlantic multidecadal oscillation also modulates summer rainfall over South China via a teleconnection pattern over Eurasia or via its impact on variation in the North Pacific (Si and Ding, 2016; Fan et al., 2018). We will show that the spring SST anomaly over the North Atlantic could be a potential predictor for HK summer rainfall.

The manuscript is organized as follows. Section Data and Methods presents the data used in this study. Seasonal forcing linked to HK summer rainfall is examined in Section Seasonal Forcing of HK Summer Rainfall. Then possible predictors are identified in Section Dynamic Mechanisms in Different Summer ENSO Phases. Section Role of Spring North Atlantic SST Anomalies summarizes the results.

\section{DATA AND METHODS}

Monthly precipitation data were extracted from the Hong Kong Observatory (HKO) Headquarters and the Climate Prediction Center Merged Analysis of Precipitation (CMAP) for the period 1979-2019. Atmospheric variables were extracted from the National Centers for Environmental Prediction-National Center for Atmospheric Research (NCEP-NCAR) global reanalysis datasets from the National Oceanic and Atmospheric Administration (NOAA) of the United States. These include the monthly fields of mean sea level pressure, multi-level wind (zonal and meridional components), omega (vertical velocity), specific humidity, and geopotential height for the period 1979-2019. The horizontal spatial resolution is $2.5^{\circ}$ latitude $\times 2.5^{\circ}$ longitude. The multi-level fields include 17 isobaric levels from $1,000 \mathrm{hPa}$ to $10 \mathrm{hPa}$, except omega includes only 11 isobaric levels from $1,000 \mathrm{hPa}$ to $100 \mathrm{hPa}$.

Monthly sea surface temperature data were extracted from the Hadley Centre sea ice and sea surface temperature dataset (HadISST) for the period 1979-2019, with a spatial resolution of $1^{\circ}$ latitude $\times 1^{\circ}$ longitude. The monthly Niño-3.4 index, obtained from the NOAA website (https://psl.noaa.gov/gcos_wgsp/ Timeseries/Data/nino34.long.anom. data), is defined as the

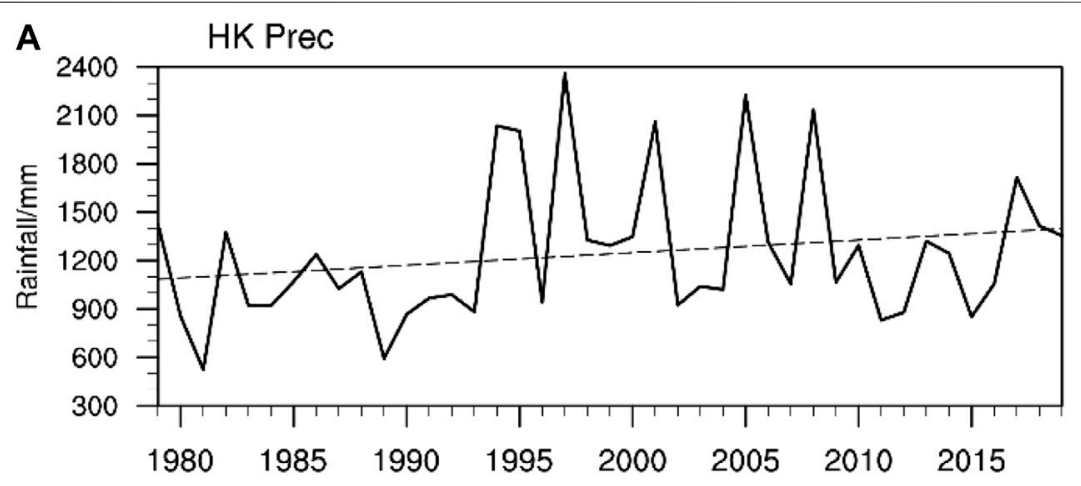

B

Reg. SLP\&Z500

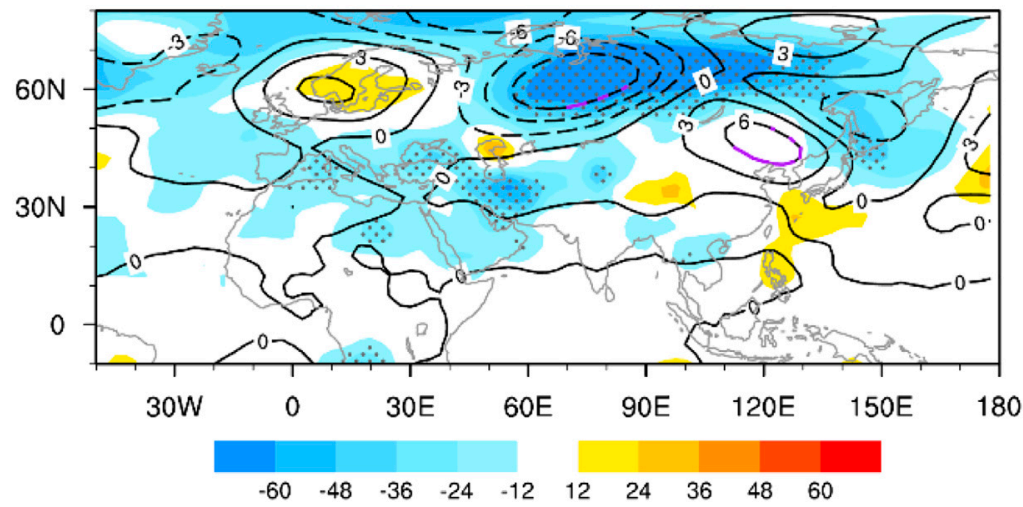

FIGURE 1 | (A) Time series of summer (June-July-August, JJA) rainfall at the HKO Headquarters (HK Prec, mm) for the period 1979-2019. (B) Regression of summer mean sea level pressure (shading, $\mathrm{Pa}$ ) and 500-hPa geopotential height (contour intervals: 3 m) onto summer HK Prec. Stippling and purple contours are significant at the $95 \%$ confidence level. 
area-averaged SST anomaly over $5^{\circ} \mathrm{S}-5^{\circ} \mathrm{N}$ and $170^{\circ}-120^{\circ} \mathrm{W}$ with respect to the 1981-2010 climatology.

The vertically integrated water vapor flux over the $1,000-300 \mathrm{hPa}$ layer (Q) is derived from the zonal and meridional components of the wind field $(U, V)$ and the specific humidity $(q)$ :

$$
Q=\frac{1}{g} \int_{1000 \mathrm{hPa}}^{300 \mathrm{ha}}(U q+V q) \mathrm{dp},
$$

where $g$ is the acceleration due to gravity.

The seasonal-mean water vapor flux $(\bar{Q})$ can be decomposed into its stationary () and transient ()$^{\prime}$ components, which represent the water vapor transport due to the seasonal-mean flow and the transient flow:

$$
\bar{Q}=\frac{1}{g} \int_{\substack{100 \mathrm{hPa} \\ \text { stationary }}}^{300 \mathrm{hPa}}(\bar{U} \bar{q}+\bar{V} \bar{q}) \mathrm{d} p+\frac{1}{g} \int_{100 \mathrm{hPa}}^{300 \mathrm{hPa}}\left(U^{\prime} q^{\prime}+V^{\prime} q^{\prime}\right) \mathrm{d} p .
$$

Because the contribution of the transient term to summer moisture transport in the tropics and South China is negligible (see Figure 5-6 in Li et al., 2013), this term can be approximated by the stationary term:

$$
\bar{Q} \approx \frac{1}{g} \int_{1000 \mathrm{hPa}}^{300 \mathrm{hPa}}(\bar{U} \bar{q}+\bar{V} \bar{q}) \mathrm{d} p,
$$

where $\bar{Q}$ is derived by the monthly $U, V$ and $q$.

The horizontal component of stationary wave activity fluxes at $250 \mathrm{hPa}(\mathrm{W})$ is used to depict Rossby wave propagation, where the direction of wave activity fluxes is parallel to the group velocity (Takaya and Nakamura, 2001):

$$
\boldsymbol{W}=\frac{p \cos \phi}{2|V|}\left\{\begin{array}{c}
\frac{\bar{U}}{a^{2} \cos ^{2} \phi}\left[\left(\frac{\partial \psi^{\prime}}{\partial \lambda}\right)^{2}-\psi^{\prime} \frac{\partial^{2} \psi^{\prime}}{\partial \lambda^{2}}\right]+\frac{\bar{V}}{a^{2} \cos \phi}\left(\frac{\partial \psi^{\prime}}{\partial \lambda} \frac{\partial \psi^{\prime}}{\partial \phi}-\psi^{\prime} \frac{\partial^{2} \psi^{\prime}}{\partial \lambda \partial \phi}\right) \\
\frac{\bar{U}}{a^{2} \cos ^{2} \phi}\left(\frac{\partial \psi^{\prime}}{\partial \lambda} \frac{\partial \psi^{\prime}}{\partial \phi}-\psi^{\prime} \frac{\partial^{2} \psi^{\prime}}{\partial \lambda \partial \phi}\right)+\frac{\bar{V}}{a^{2}}\left[\left(\frac{\partial \psi^{\prime}}{\partial \phi}\right)^{2}-\psi^{\prime} \frac{\partial^{2} \psi^{\prime}}{\partial \phi^{2}}\right]
\end{array}\right\},
$$

where the overbar denotes the climatological mean, $p$ is $250 \mathrm{hPa}$, and $\psi^{\prime}$ is the perturbation streamfunction derived from the regressed wind field.

\section{SEASONAL FORCING OF HK SUMMER RAINFALL}

Climatologically, the accumulated $\mathrm{HK}$ rainfall in boreal summer (June-July-August) is $1,235 \mathrm{~mm}$ during the period of 1979-2019, accounting for more than $50 \%$ of the total annual rainfall. The summer rainfall has strong interannual variation (Figure 1A), with two interdecadal turning points at 1993/1994 and 2009/2010. These interdecadal shifts are consistent with the SCSSM onset, which occurred earlier from 1993 to 1994 and became normal or occurred later in about 2010 (Wang et al., 2004; Wu et al., 2010; Kajikawa and Wang, 2012; Fan et al., 2014; Liu et al., 2016; Li et al., 2019b). Such a coincidence suggests a coherent relationship between the SCSSM onset and HK summer rainfall. Note that the slightly increasing trend of precipitation during the study period (the dashed line in Figure 1A) might indicate more precipitation in HK under global warming (Leung et al., 2004).

It is curious how strongly summer rainfall in $\mathrm{HK}$ is modulated by large-scale forcing from both the midlatitudes and the tropics. To identify the strongest seasonal large-scale forcing linearly related to summer rainfall in $\mathrm{HK}$, a time series of normalized $\mathrm{HK}$ summer rainfall is regressed onto mean sea level pressure and $500-\mathrm{hPa}$ geopotential height (Figure 1B). Although the strength of the western North Pacific subtropical high affects the intensity of the East Asian summer monsoon (e.g., Huang and Wu, 1989; Zhang et al., 1999; Chang et al., 2000), it is not statistically significant in relation to summer rainfall in HK. Instead, the year-to-year variation in summer rainfall in $\mathrm{HK}$ is significantly linearly correlated with the midlatitude circulation over central and East Asia. Specifically, more (less) summer rainfall in HK is associated with negative (positive) pressure anomalies centered over Ural-Siberia. It is also associated with positive (negative) pressure anomalies over Europe, but this signal is not significant. The linkage between summer rainfall in HK and the large-scale teleconnection over midlatitude Eurasia is noteworthy. It should be noted that the result is similar when the above analysis is repeated using the summer rainfall at stations along the South China coast.

In boreal summer, the Ural Mountains form one of the major blocking sectors in the Northern Hemisphere. The occurrence of a Ural blocking high advects more cold air from the high latitudes to Siberia. The associated cold air activity can enhance frontal precipitation when it meets warm and moist air from lower latitudes. The persistence of summer Ural blocking has been identified as one of the main dynamic causes of flooding near the
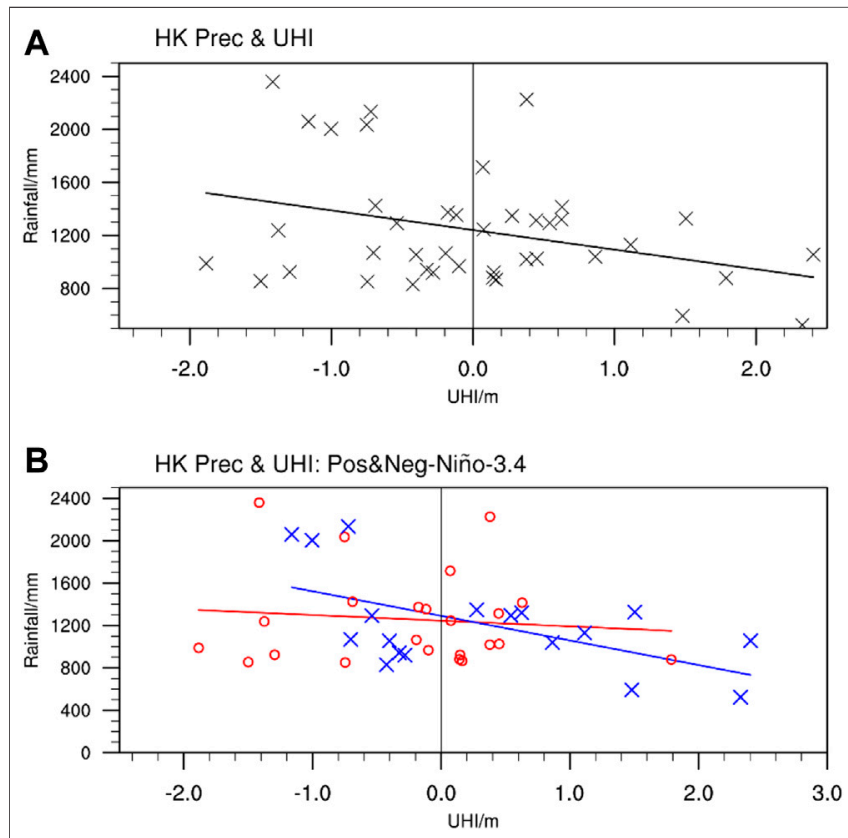

FIGURE 2 | (A) Scatterplot of HK Prec $(\mathrm{mm})$ against the standardized Ural Height Index (UHI, $\mathrm{m})$ in summer, where the straight line represents the least square fit. (B) Same as (A), but for positive Niño-3.4 summers (red) and negative Niño-3.4 summers (blue). 
Yangtze River, as occurred in 1998 (Li et al., 2001), but a linkage between Ural blocking and summer rainfall in $\mathrm{HK}$ has not previously been revealed. Because we focus on seasonal-mean circulation, we define a Ural height index (UHI) as the standardized June-July-August (JJA) geopotential height averaged over $50^{\circ}-70^{\circ} \mathrm{N}$ and $45^{\circ}-90^{\circ} \mathrm{E}$ during 1979-2019. As shown in Figure 2A, the UHI against HK summer rainfall is significantly negatively correlated, where the correlation is -0.334 and exceeds the $95 \%$ confidence level. Such an inverse relationship suggests that more occurrence of Ural blocking is associated with less summer rainfall in HK. That means the relationship between Ural blocking and summer rainfall in the Yangtze River and HK (and the South China coast) is reversed. Before investigating the possible dynamic mechanism responsible for the above linkage, we would like to identify the pre-season signals of these circulation anomalies, which could be useful for seasonal forecasts.

Operationally, the seasonal prediction of HK summer rainfall has relied on SST, especially over the tropical Pacific (Chang and Yeung, 2003). However, we do not find a significant statistical relationship between the tropical SST and summer rainfall in $\mathrm{HK}$. As shown in Figures 3A,B, summer rainfall in $\mathrm{HK}$ is also not significantly correlated with SST over the tropical Pacific during the concurrent summer and spring. The correlation between the Niño-3.4 index and HK summer rainfall is +0.109 during the period 1979-2019, where the average summer rainfall in positive and negative Niño-3.4 summers is $1,258 \mathrm{~mm}$ and $1,230 \mathrm{~mm}$, respectively. It appears that Pacific SST cannot well predict summer rainfall in $\mathrm{HK}$. Instead, the rainfall is moderated linked to SST over part of the North Atlantic in spring and summer. The lead-lag correlation (Figure 3C) between $\mathrm{HK}$ summer rainfall and North Atlantic SST over $30^{\circ}-60^{\circ} \mathrm{N}$ and $45^{\circ}-15^{\circ} \mathrm{W}$ in different seasons (SST-Atl, black boxes in Figures 3A,B) shows a significant positive correlation that peaks in spring. Therefore, the spring SST-Atl is a potential seasonal predictor for summer precipitation in HK.

It is also important to see whether the seasonal predictor of the $\mathrm{UHI}$ is the same as that of summer rainfall in $\mathrm{HK}$, because the UHI and HK summer precipitation are moderately correlated. As shown in Figures 3D-F, the UHI is significantly correlated with SST in part of the North Atlantic and the tropical south Atlantic from spring to summer. It is also moderately correlated with SST in the Niño-3.4 region over the tropical Pacific during summer (Figure 3E). This is different from the insignificant correlation between summer rainfall in HK and SST over the tropical Pacific. When the summer UHI is correlated with SST in different seasons, we can observe the evolution of a La Niña-like pattern from the concurrent spring to the concurrent fall (figures not shown). This relationship can be depicted by a significant negative correlation between the UHI and the Niño-3.4 index (dotted dashed line in Figure 3F). In other words, a summer with a negative (positive) Niño-3.4 index is

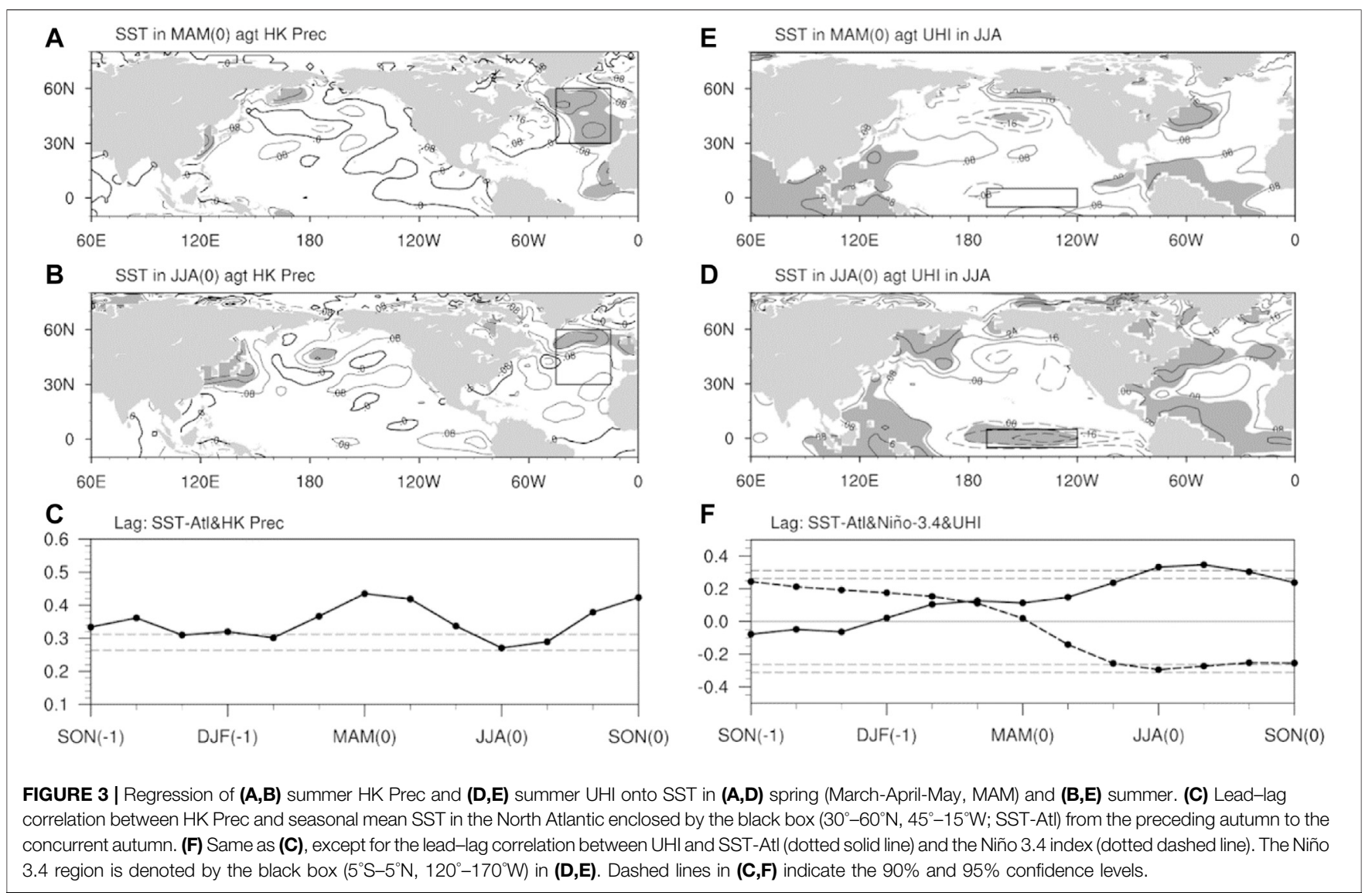




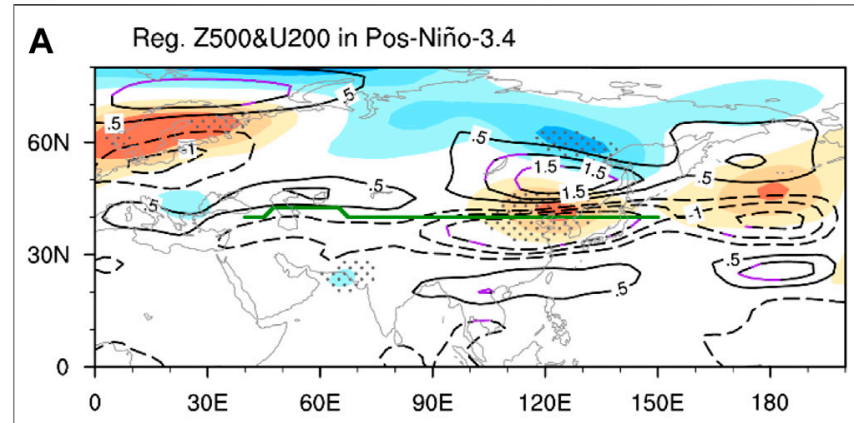

B Reg. Z500\&U200 in Neg-Niño-3.4

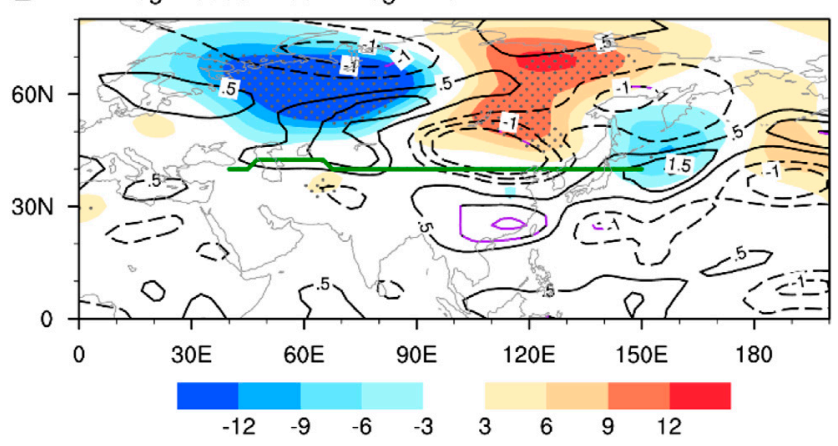

FIGURE 4 | Regression of summer 500-hPa geopotential height (shading, $\mathrm{m}$ ) and 200-hPa zonal winds (contour interval: $0.5 \mathrm{~m}$, zero contours are omitted) onto summer HK Prec for years with (A) a positive Niño 3.4 summer and (B) a negative Niño 3.4 summer. Stippling and purple contours indicate the $90 \%$ confidence level. The thick green line shows the climatological location of the westerly jet axis at $200 \mathrm{hPa}$.

more likely to have a positive (negative) UHI, which tends to be associated with less (more) summer rainfall in HK. However, while the UHI is significantly correlated with both the Niño-3.4 index and summer rainfall in $\mathrm{HK}$, summer rainfall in $\mathrm{HK}$ is significantly correlated only with the UHI. The relationship between the UHI and summer rainfall in $\mathrm{HK}$ seems to be modulated by the phase of ENSO.

To examine the impact of ENSO, the study period is divided into positive (Niño-3.4 index $>0$ ) and negative (Niño-3.4 index $<0$ ) ENSO summers, specifically with 23 positive years and 18 negative years. Figure 2B shows that the linear relationship between the UHI and $\mathrm{HK}$ summer rainfall is strong (weak) in the negative (positive) phase of summer ENSO, where the linear correlation coefficient in the negative ENSO phase is -0.565 (exceeding the $95 \%$ confidence level). This asymmetric relationship suggests that the large-scale atmospheric forcing associated with $\mathrm{HK}$ summer rainfall is different in the two ENSO phases. Accordingly, in the following section the summer large-scale circulations are regressed against HK summer rainfall in positive and negative Niño-3.4 years separately.

\section{DYNAMIC MECHANISMS IN DIFFERENT SUMMER ENSO PHASES}

During positive Niño-3.4 years, HK summer rainfall is associated with a north-south oriented dipole-like height anomaly pattern over extratropical East Asia (Figure 4A). The negative anomalies at $60^{\circ} \mathrm{N}$ imply a weaker Okhotsk high and the positive anomalies at $40^{\circ} \mathrm{N}$ imply a weaker vortex over northeastern China. The positive height anomaly center is close to the climatological jet axis at $200 \mathrm{hPa}$. Correspondingly, the upper-tropospheric zonal winds south of the climatological jet location are weakened. The pronounced positive (negative) zonal wind anomalies at $50^{\circ} \mathrm{N}$ $\left(35^{\circ} \mathrm{N}\right)$ suggest a northward (southward) shift of the westerly jet during positive Niño-3.4 years, with more (less) HK summer rainfall. The South China coast has slightly stronger zonal wind corresponding to more rainfall. These circulation anomalies are associated with the southward propagation of wave activity fluxes from North China to South China (Figure 5A). Besides the signal over East Asia, it is noticeable that HK summer rainfall in positive Niño-3.4 years is associated with positive height anomalies over Scandinavia (Figure 4A). However, its associated Rossby wave train propagates southeastward toward the Mediterranean and the Middle East, and it does not propagate farther toward East Asia. In short, the pronounced forcing of large-scale circulation related to $\mathrm{HK}$ summer rainfall in positive Niño-3.4 years is confined to East Asia.

During negative Niño-3.4 years, on the other hand, the largescale circulation anomalies associated with $\mathrm{HK}$ summer rainfall indicate stronger tropical-midlatitude interactions (Figure 4B). The extratropical Eurasian continent has a strong zonal dipole pattern, with a center of action over the Urals and another center of action over the middle and high latitudes of Asia. The positive anomalies over Asia are associated with weaker zonal winds north of the climatological jet axis. The pronounced positive zonal wind anomalies over the South China coast suggest a southward shift of the westerly jet. The above results suggest that during negative Niño-3.4 years, the positive (negative) UHI tends to be accompanied by stronger (weaker) westerlies near the climatological jet and weaker (stronger) zonal wind over the
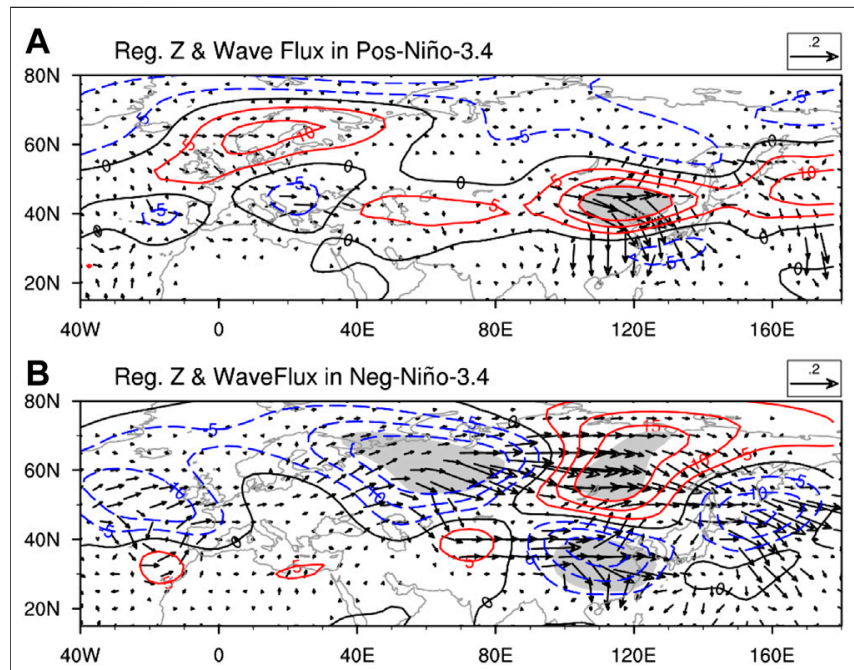

FIGURE 5 | Regression of summer 200-hPa geopotential height (contour, $\mathrm{m}$ ) and wave activity flux (arrows, $\mathrm{m}$ ) onto summer HK Prec for years with (A) a positive Niño-3.4 index and (B) a negative Niño-3.4 index. Shading indicates the $90 \%$ confidence level. 


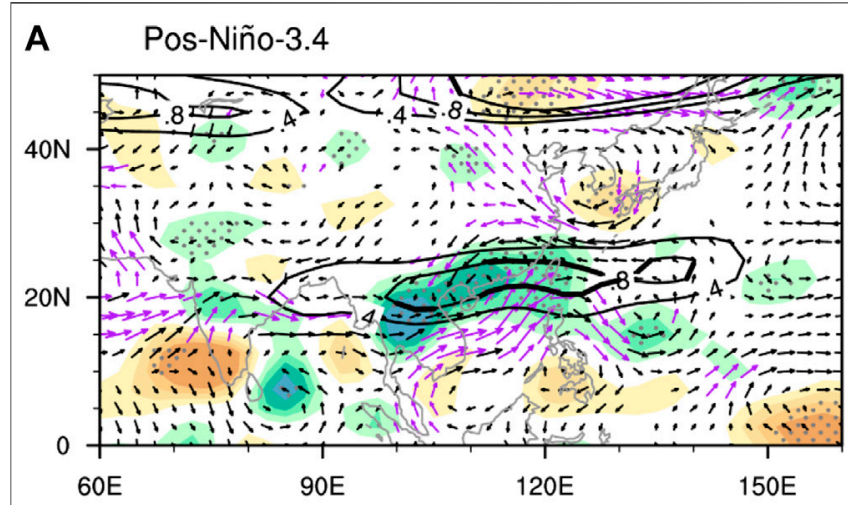

B Neg-Niño-3.4

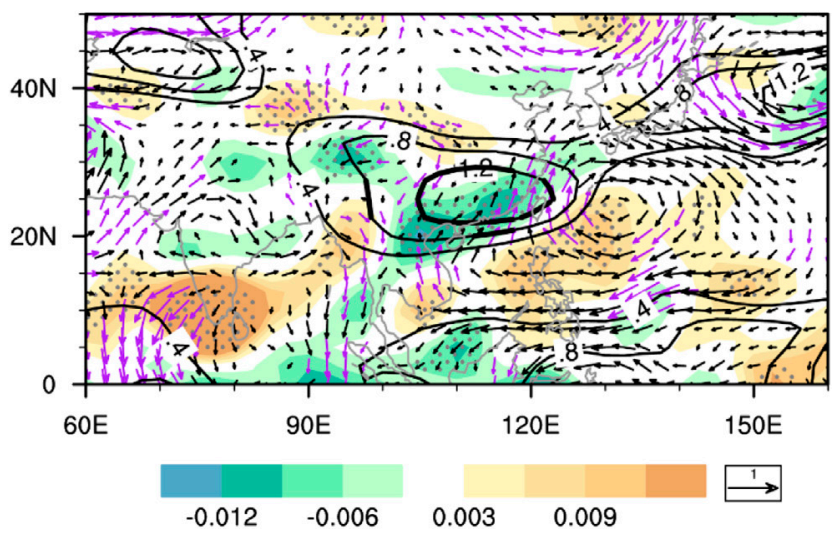

FIGURE 6 | Regression of summer 500-hPa vertical velocity (shading, $\mathrm{Pa} \mathrm{s}^{-1}$ ), 200-hPa zonal winds (black contours, m/s), and 850-hPa winds (arrows, m/s) onto summer HK Prec for years with (A) a positive Niño-3.4 index and (B) a negative Niño-3.4 index. Stippling, thick black contours, and purple arrows are significant at the $90 \%$ confidence level.

South China coast. This results in less (more) rainfall in HK. These circulation anomalies are associated with pronounced Rossby wave trains propagating from the Urals to East Asia (Figure 5B). One of the wave trains propagates toward the positive height anomalies over the high latitudes of Asia, where the wave train is split into two branches. One branch propagates southeastward toward the North Pacific, and the other branch propagates southward to East Asia via the Tibetan Plateau. Therefore, the $\mathrm{HK}$ summer rainfall anomalies in negative Niño-3.4 years are strongly influenced by large-scale forcing over the Urals.

Comparatively, the $500-\mathrm{hPa}$ height regression pattern associated with $\mathrm{HK}$ summer rainfall in negative Niño-3.4 years (Figure 4B) strongly resembles the regression pattern associated with $\mathrm{HK}$ summer rainfall in all years (Figure 1B), including negative height anomalies over the Ural-Siberian region and positive height anomalies over the high latitudes of northern Asia. This is expected because of the much stronger linear correlation between the UHI and $\mathrm{HK}$ rainfall in negative Niño-3.4 years. However, the positive regressed height anomalies over northeastern China are captured only by positive Niño-3.4 years (Figure 4A); in negative Niño-
3.4 years the positive regressed height anomalies are located at a higher latitude (Figure 4B). Corresponding to a distinct regressed height pattern, the upper-tropospheric zonal wind anomalies associated with HK rainfall in the two ENSO phases are different. Whereas the upper-tropospheric jet stream shifts meridionally over the midlatitudes of East Asia during positive Niño-3.4 years (Figure 4A), it shifts meridionally with a center over South China during negative Niño-3.4 years (Figure 4B). Apparently, the anomalies of $\mathrm{HK}$ summer rainfall in the two ENSO phases have different dynamics.

Besides the difference in large-scale circulations, the South China circulation anomalies associated with HK summer rainfall in the two ENSO phases are different (Figure 6). During positive Niño-3.4 years, strong lower-level convergence associated with enhanced HK summer rainfall is concentrated over southern China (Figure 6A). The associated southwesterlies extends from the Indian Ocean to the South China Sea, where the southwesterlies become more strengthened and zonally oriented, indicating a strong lower-level westerly jet. The corresponding upper-tropospheric jet stream is located northeast of the lower-tropospheric westerly jet stream, which extends zonally along $20^{\circ} \mathrm{N}$ from the Indochina Peninsula to the western North Pacific. The South China coast is located at the gap between the upper-tropospheric and lower-tropospheric jet streams, i.e., south of the upper-tropospheric jet and north of the lower-tropospheric jet. Correspondingly, this region has anticyclonic vorticity anomalies in the upper troposphere and cyclonic vorticity anomalies in the lower troposphere. These trigger stronger rising motion (shading in Figure 6A) and more precipitation over the South China coast. Specifically, the lower-tropospheric westerlies transport more water vapor from the Indian Ocean to the South China Sea. Therefore, HK rainfall anomalies during positive Niño-3.4 years are driven mainly by the local jet-precipitation dynamic processes and water vapor transport from the Indian Ocean.

During negative Niño-3.4 years, The upper-tropospheric zonal wind anomalies over South China are much stronger than their positive Niño-3.4 counterpart (Figure 6A), while the lower-tropospheric cyclonic anomalies are weak over the tropical Indo-Pacific Ocean and South China with weaker northerlies from mid-latitudes and enhanced southerlies associated with anticyclonic anomalies east of the Philippines (Figure 6B). As mentioned previously, the upper-tropospheric jet stream tends to shift southward associated with HK summer rainfall anomalies in negative Niño-3.4 years. Because the South China coast is located southwest of the maximum zonal wind anomalies (Figure 6B), the corresponding anomalous uppertropospheric divergence $(\delta \mathrm{u} / \delta \mathrm{x}>0)$ can enhance anomalous rising motion over this region. On the other hand, the anomalous sinking motion over the Philippines is associated with less rainfall. This also accompanies an anomalous anticyclone transporting more water vapor toward the South China coast via the South China Sea. Therefore, the anomalies of HK summer rainfall in negative Niño-3.4 years are a result of the southward shift of a stronger or weaker upper-tropospheric jet stream toward South China and water vapor transport associated with the anomalous Philippine Sea anticyclone. 

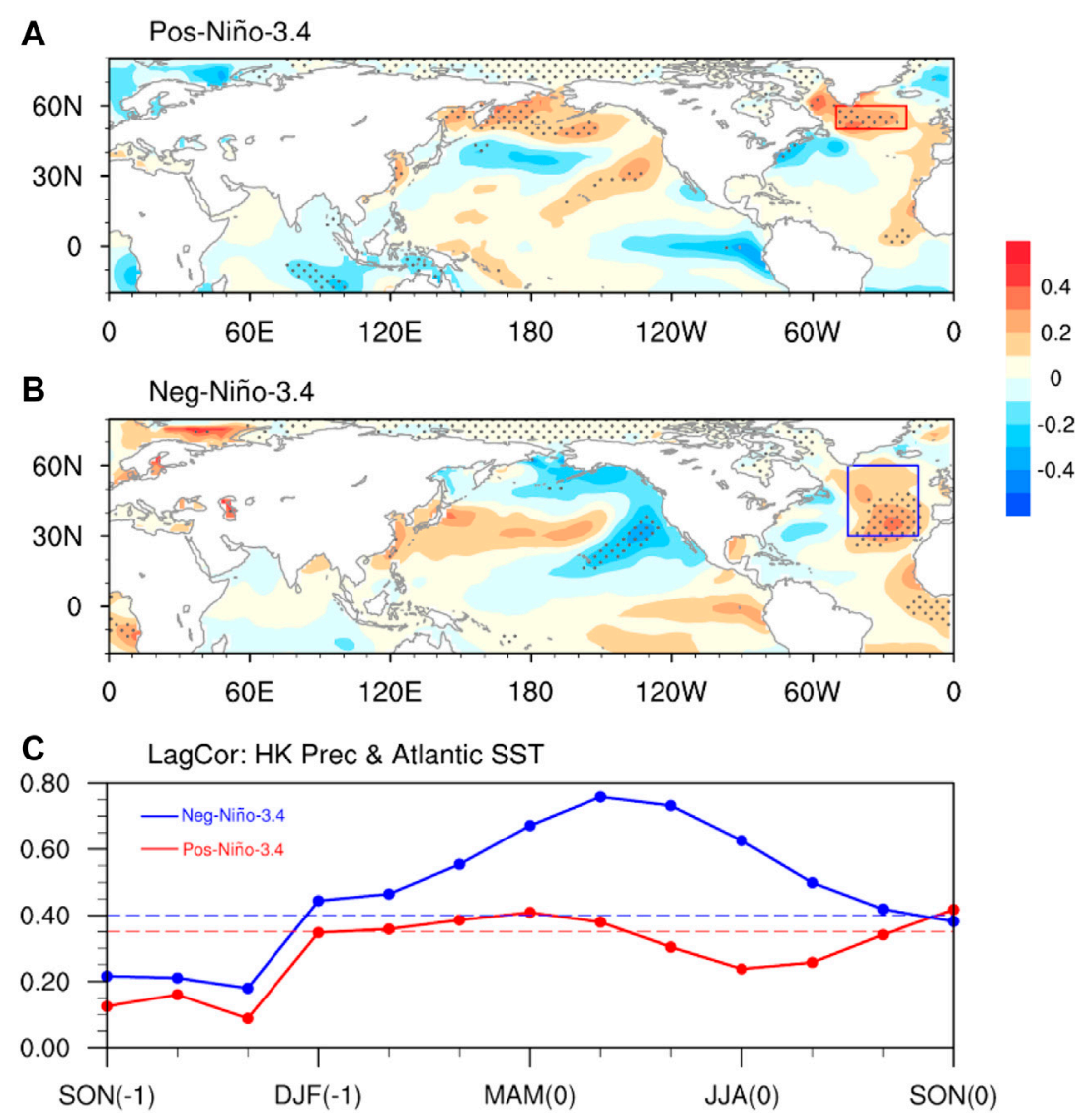

FIGURE 7 | Regression of spring SST (K) onto summer HK Prec for years with (A) a positive Niño-3.4 summer and (B) a negative Niño-3.4 summer. Stippling indicates the $90 \%$ confidence level. (C) Lead-lag correlation between HK Prec and seasonal mean SST-Atl-P for positive Niño-3.4 summers (red) and seasonal mean SST-Atl for negative Niño-3.4 summers (blue). Dashed lines indicate the $90 \%$ confidence level.

\section{ROLE OF SPRING NORTH ATLANTIC SST ANOMALIES}

Now that we have identified the large-scale forcing responsible for HK summer rainfall anomalies in the two ENSO phases in Section Dynamic Mechanisms in Different Summer ENSO Phases, in this section we would like to further depict the precursory signals that could explain HK summer rainfall anomalies in these phases. As mentioned in Section Seasonal Forcing of HK Summer Rainfall, the spring SST-Atl is a potential precursor of HK summer rainfall (Figure 3A). However, this relationship is much stronger in negative Niño-3.4 summers (Figure 7B) and weaker during positive Niño-3.4 summers (Figure 7A). In negative Niño-3.4 years, the correlation between HK summer rainfall and SST-Atl in different months is significant from the preceding winter to the concurrent summer (Figure 7C). The above statistical analysis suggests that SST-Atl is a potential seasonal predictor of $\mathrm{HK}$ summer rainfall in negative Niño-3.4 years. Conversely, in positive Niño3.4 years, HK summer rainfall is weakly correlated with SST-Atl because it is not correlated with the midlatitude North Atlantic SST captured by SST-Atl. Instead, HK summer rainfall in positive years is moderately correlated with the subpolar North Atlantic, which can be represented by an index called SST-Atl-P $\left(50^{\circ}-60^{\circ} \mathrm{N}\right.$, $50^{\circ}-20^{\circ} \mathrm{W}$; Figure $7 \mathrm{C}$ ). In the following, we will show how the spring SST-Atl and SST-Atl-P can affect HK summer rainfall in negative Niño-3.4 years and positive Niño-3.4 years, respectively.

\section{Negative ENSO Phase}

Warmer spring and summer SST-Atl is associated with abovenormal rainfall over South China (Figures 8A,B) and belownormal rainfall spreading from the eastern Indochina Peninsula to the western North Pacific. Such a dipole-like rainfall regression pattern resembles the regression pattern against $\mathrm{HK}$ summer rainfall (Figure 5B). Such a resemblance suggests an impact of the spring SST-Atl on HK summer rainfall. Moreover, the dipole-like rainfall regression pattern is associated with an anomalous anticyclonic circulation east of the Philippines. The southwesterly winds west of the anticyclonic anomaly convey abundant water vapor from the western North Pacific to South China. The convergence of water vapor over South China can enhance rainfall locally. Therefore, the anomalous Philippine Sea anticyclone is crucial for inducing stronger summer rainfall in HK. This anticyclone appears to be stronger when the warming of SST-Atl persists from spring to summer during negative Niño3.4 years (Figure $\mathbf{8 B}$ ). 


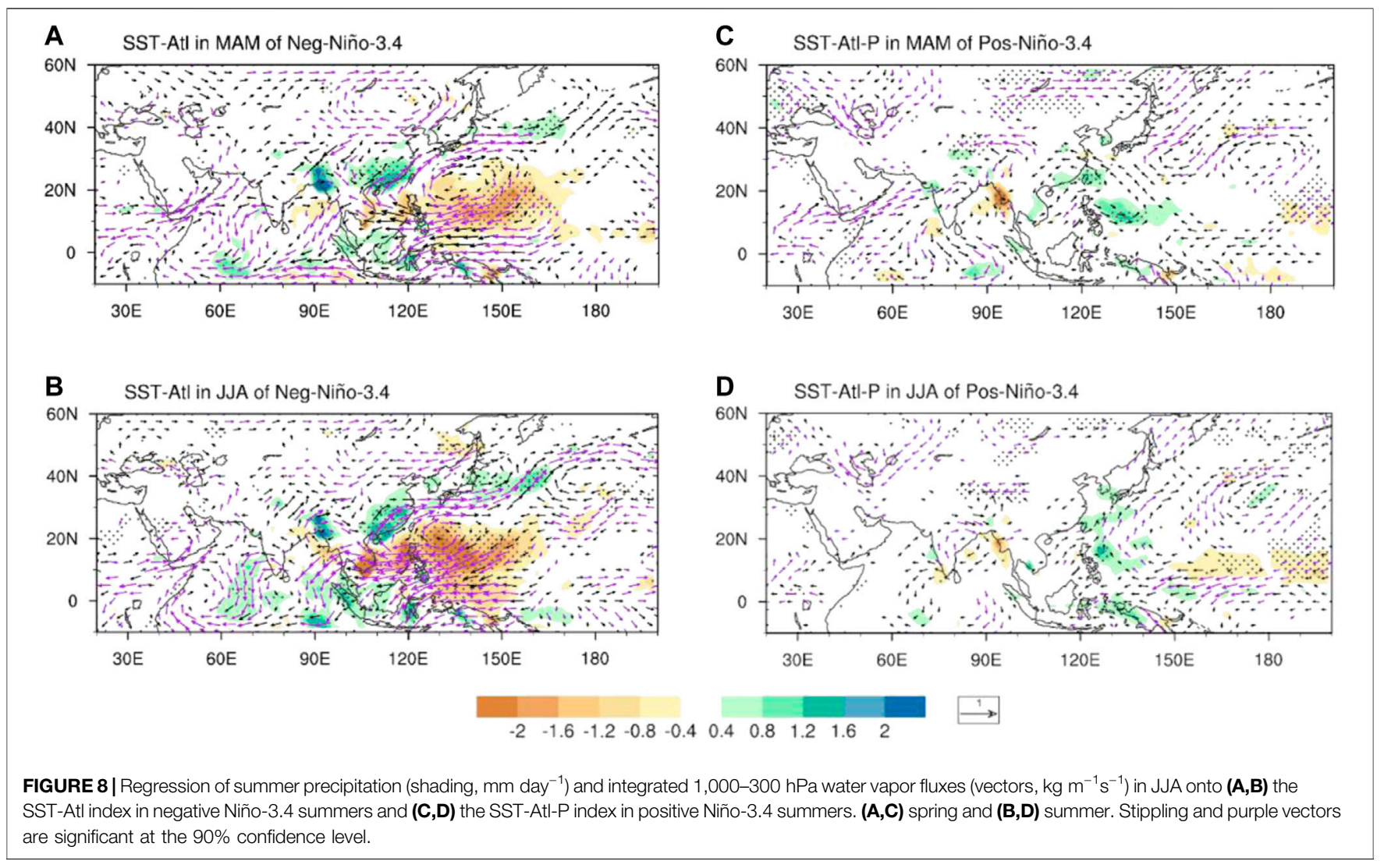

The time-lagged impact of the spring SST-Atl on the largescale atmospheric circulation is further investigated in Figures 9A-D. In spring, warmer SST-Atl is associated with a "positive north-negative south" dipole anomaly over the North Atlantic (Figure 9A), which partly resembles the negative phase of the North Atlantic Oscillation. The dipole anomaly accompanies wave trains propagating eastward from the North Atlantic. The propagation is separated into two pathways over the eastern Atlantic (Figure 9A). The first wave train travels at the middle and high latitudes across Europe and the Barents Sea to the Ural Mountains. The second wave train travels across northern Africa to the Middle East. The northern wave train is more closely linked to the negative anomaly centered at $40^{\circ} \mathrm{N}$ over East Asia. From spring to summer, whereas the dipole anomaly over the North Atlantic associated with SST-Atl weakens and moves eastward, it persistently affects the East Asian circulation via the aforementioned two wave trains, especially the highlatitude wave train (Figures 9B-D). This corresponds to the persistence of a negative height anomaly near the Barents Sea and the Ural Mountains. The tropical-midlatitude interactions associated with the Ural height anomaly could explain the influence of SST-Atl on HK summer rainfall.

The summer Ural low (high) anomaly is associated with cyclonic flow (anticyclonic flow) over the southern part of the East Asian continent (figure not shown; can be deduced by Figures 5B, 9D). This is accompanied by subtropical westerly (easterly) wind anomalies over South China. This is also linked to stronger (weaker) western North Pacific subtropical high because
South China is located at the northern edge of the western North Pacific subtropical high. Such an influence can also be inferred by the southeastward propagation of the Rossby wave train toward the tropical western Pacific (Figure 9D). Accordingly, when SSTAtl is persistently warmer (cooler) from spring to summer during negative Niño-3.4 years, the summer Ural low (high) anomaly strengthens (weakens) the western North Pacific subtropical high. The associated southwesterly wind toward the South China coast (Figures 8A,B) enhances (reduces) HK summer rainfall.

In short, the summer in $\mathrm{HK}$ is expected to have more rainfall when the warming of SST-Atl persists from spring to summer in negative Niño-3.4 years. The SST-Atl anomaly influences HK summer rainfall via large-scale teleconnection with a center of action near the Ural Mountains.

\section{Positive ENSO Phase}

The spring and summer SST-Atl-P is not strongly linked with summer large-scale atmospheric circulation (Figures 8C,D). Although the spring SST-Atl-P is moderately correlated with HK summer rainfall (Figure 7C), it is only weakly correlated with rainfall over South China (Figure 8C). Moreover, warmer spring SST-Atl-P is associated with slightly above-normal rainfall east of the Philippine Sea and a weak cyclonic flow over the western North Pacific and the South China Sea (Figure 8C). This suggests that the spring North Atlantic SST in positive Niño-3.4 years does not modulate HK summer rainfall via enhancing water vapor transport associated with the Philippine Sea anticyclone. 


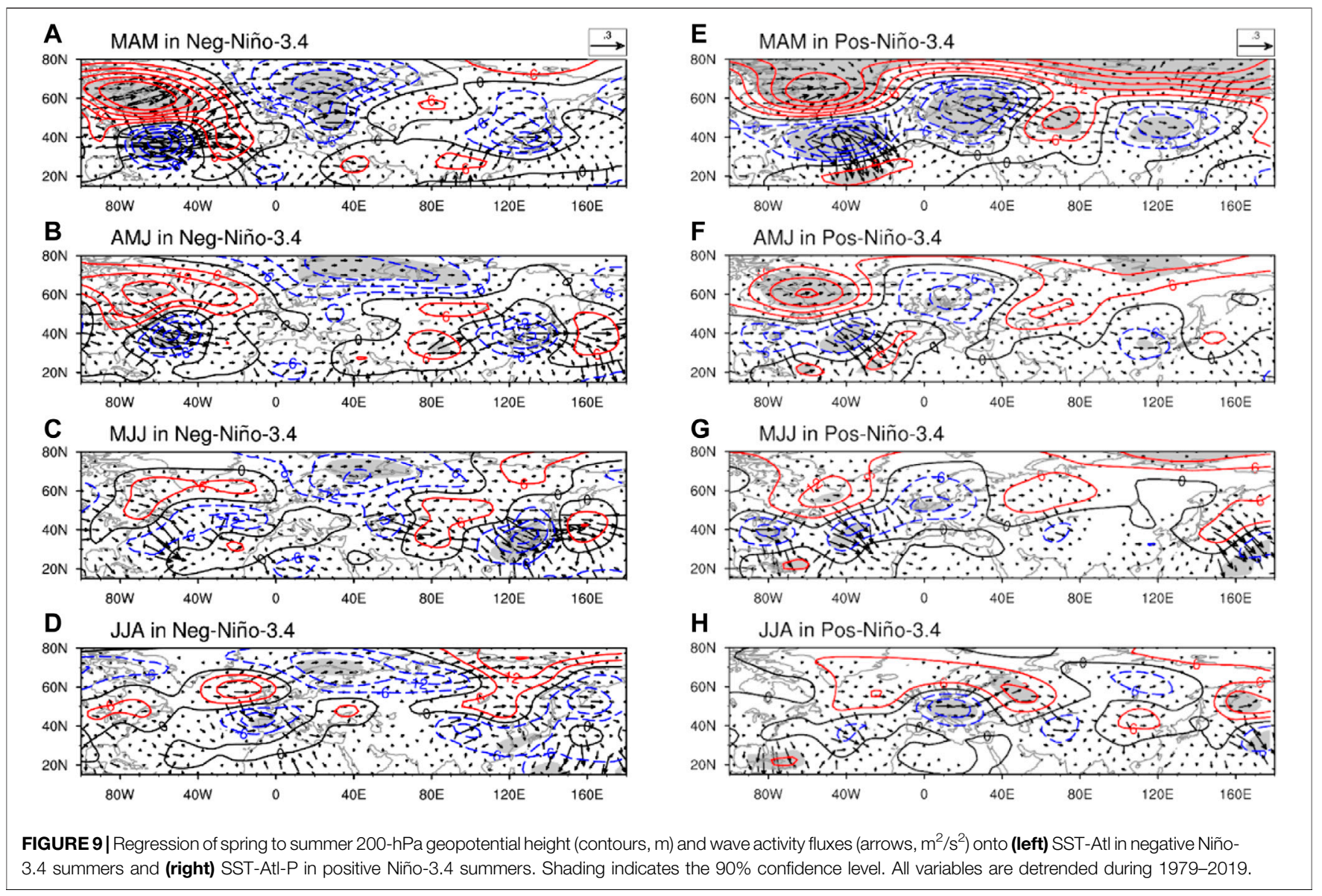

Indeed, the positive $\mathrm{HK}$ summer rainfall anomaly in positive Niño-3.4 years is associated with a remarkable high anomaly over northeastern China, a weak high anomaly over Scandinavia, and a weak low anomaly over central Europe (Figure 4A). To further depict how much the spring SST-Atl-P modulates the aforementioned large-scale circulation anomalies, the spring SST-Atl-P is regressed onto the spring-to-summer 200-hPa height and wave activity fluxes (Figures 9E-H). During spring, the large-scale circulation features associated with warmer SST-Atl-P during positive Niño-3.4 years (Figure 9E) is similar to those associated with warmer SST-Atl during negative Niño-3.4 years (Figure 9A). These features include a dipole-like anomaly over the North Atlantic and a midlatitude wave train across Eurasia (Figure 9E). The wave train in positive Niño-3.4 years (Figure 9E) is even stronger than its counterpart (Figure 9A), with pronounced centers of action over northeastern Europe $\left(\sim 30^{\circ} \mathrm{E}\right)$, the Urals $\left(\sim 70^{\circ} \mathrm{E}\right)$, and northeastern China $\left(\sim 120^{\circ} \mathrm{E}\right)$. However, the low anomaly over northeastern China substantially weakens from spring to early summer (Figures 9E-G), and its sign is reversed in summer (Figure 9H). This is different from the progressive southward migration of the low anomaly over East Asia during negative Niño-3.4 years (Figures 9A-C). Meanwhile, the low anomaly over Europe moves southwestward from northeastern Europe in spring to central Europe in summer (Figures 9E-H), which accompanies a westward shift of the high anomaly over the Urals. The associated wave activity fluxes propagate southeastward from the Urals to East Asia via South Asia (Figure 9H). This partly explains the high anomaly over northeastern China associated with the HK summer rainfall anomaly (Figure $\mathbf{5 A}$ ).

Therefore, the spring SST anomaly over the North Atlantic cannot well explain the HK summer rainfall anomaly during positive Niño-3.4 years. Besides the SST signal, it is noticeable that warmer SST-Atl-P in positive Niño-3.4 years is accompanied by positive height anomalies over the Arctic in spring (Figure 9E). This is related to weakening of the stratospheric polar vortex associated with a warmer North Atlantic. We found that $\mathrm{HK}$ summer rainfall is also significantly correlated with the 10-hPa geopotential height over the North Pacific in the preceding winter. However, the stratospheric signal also cannot well explain the large-scale circulation anomalies associated with the HK summer rainfall anomaly (figures not shown).

\section{SUMMARY AND DISCUSSION}

Although HK is located adjacent to the South China Sea, the interannual variation of HK summer rainfall during the period 

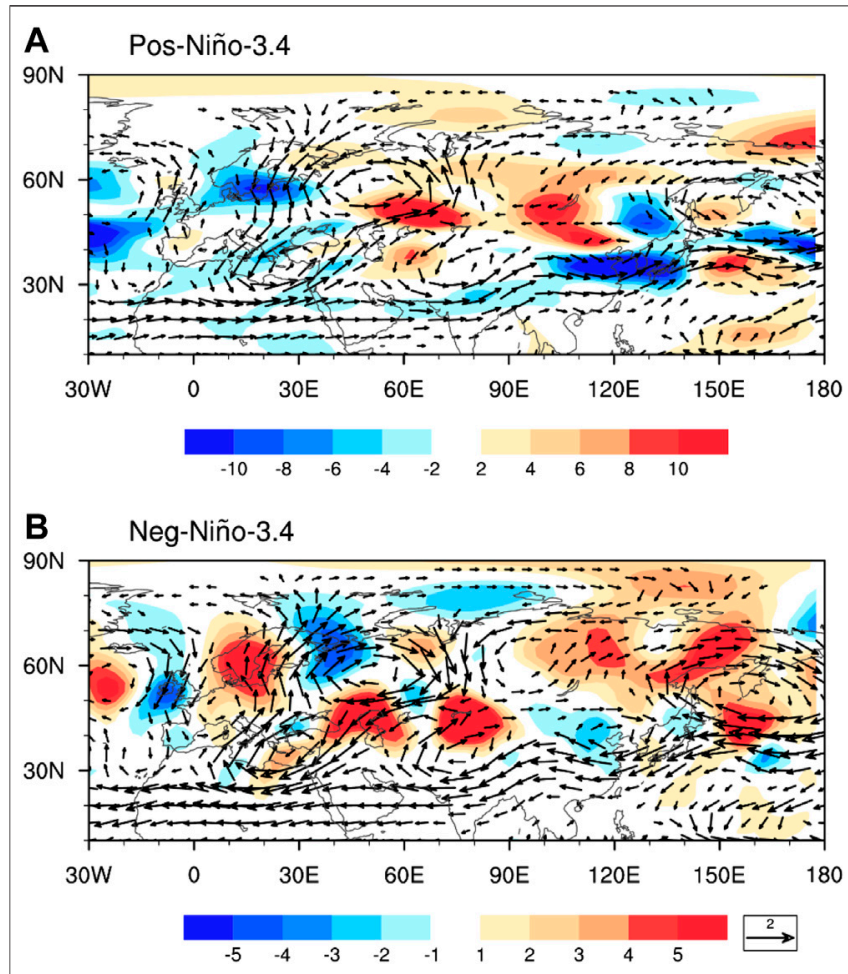

FIGURE 10 | Composite of the 200-hPa wind anomalies (arrows) in (A) positive and (B) negative Niño 3.4 summers (June-July-August). Difference in the interannual variance of the (A) 200-hPa zonal wind (shading) and (B) meridional wind (shading) between negative and positive Niño 3.4 summers (negative minus positive). Note that the scale of shading in (A) is two times that in (B). Unit: $\mathrm{m} / \mathrm{s}$.

1979-2019 is not strongly correlated with tropical forcing, such as the intensity of the western North Pacific subtropical high and ENSO. Instead, HK summer rainfall is significantly correlated with summer circulation anomalies over the Ural-Siberian region $\left(50^{\circ}-70^{\circ} \mathrm{N}, 45^{\circ}-90^{\circ} \mathrm{E}\right)$. Therefore, from a forecasting perspective, HK summer rainfall cannot be well predicted by the ENSO signal, which is an important precursor of East Asian summer monsoon intensity on interannual timescales. We have shown that the spring SST-Atl (North Atlantic SST) is a potential seasonal predictor for HK summer rainfall, where warmer spring North Atlantic SST tends to be followed by negative Ural height anomalies in summer and more $\mathrm{HK}$ summer rainfall. It should be noted that the relationship among SST-Atl, the summer Ural circulation, and $\mathrm{HK}$ summer rainfall is strong during negative Niño-3.4 summers and weak during positive Niño-3.4 summers.

In negative Niño-3.4 summers, HK summer rainfall is robustly correlated with SST-Atl from the preceding winter to the concurrent autumn. The persistent warming of SST-Atl from spring to summer is associated with a dipole-like pattern over the North Atlantic, where an anomalous high is located at high latitudes. This is associated with a Rossby wave train emanating from the North Atlantic and propagating to East Asia across the middle and high latitudes of Eurasia. Specifically, a low anomaly is located over the Barents Sea and a high anomaly is located over the

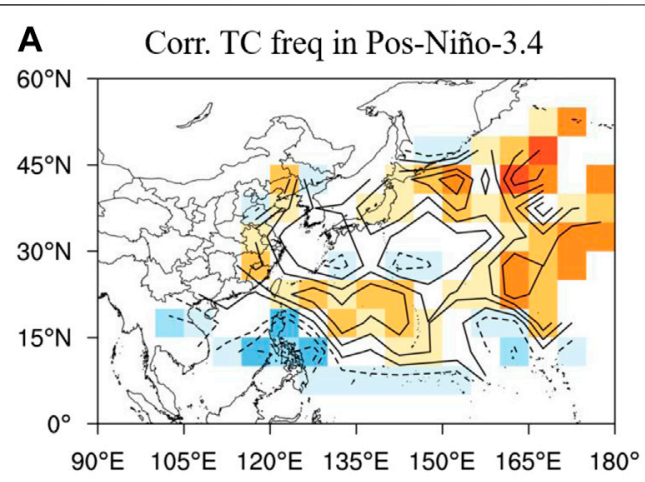

B $\quad$ Corr. TC freq in Neg-Niño-3.4

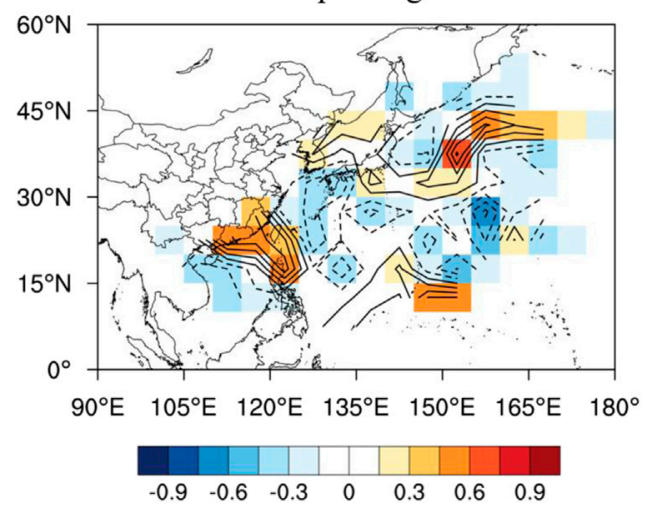

FIGURE 11 | Correlation between summer HK Prec and tropical cyclone track density in (A) positive Niño-3.4 summers and (B) negative Niño-3.4 summers. Tropical cyclone tracks were obtained from the Joint Typhoon Warning Center (https://www.metoc.navy.mil/jtwc/jtwc.html?westernpacific).

high latitudes of Asia. This is associated with a southeastward propagation of a Rossby wavetrain toward subtropical East Asia and the tropical Pacific. This accompanies a stronger uppertropospheric westerly jet shifting southward toward South China and a stronger Philippine Sea anticyclone. The latter enhances water vapor transport toward South China and contributes to more rainfall in HK. Hence, the HK summer rainfall anomaly in negative Niño-3.4 summers is associated with strong tropical-midlatitude interactions.

In positive Niño-3.4 summers, on the other hand, HK summer rainfall is moderately correlated with the spring North Atlantic SST over the subpolar region (SST-Atl-P). However, the significant correlation between HK summer rainfall and SSTAtl-P does not persist in other months. The spring SST-Atl-P is associated with a pronounced Rossby wave train across the middle and high latitudes of Eurasia in spring, but this wave train weakens substantially in early summer. The spring SST-Atl$\mathrm{P}$ is associated with a Rossby wave train propagating southeastward from eastern Europe to East Asia via South Asia in summer. This partly explains the high anomaly over northeastern China. Indeed, HK summer rainfall in positive Niño-3.4 summers is associated with southward propagation of wave activity fluxes from midlatitude East Asia to South 
China, which accompanies pronounced height anomalies confined to northeastern Asia. The rainfall anomaly in HK is largely modulated mainly by anomalies in westerly jets. This is related to enhanced upper-tropospheric and lower-tropospheric jet streams in subtropical Asia, where the lower-tropospheric wind anomaly is located south of the upper-tropospheric wind anomaly. The stronger westerly winds enhance the rising motion over $\mathrm{HK}$ and bring more water vapor from the Indian Ocean and Bay of Bengal to South China. Thus, tropical forcing may also play an important role in triggering rainfall anomalies in positive Niño-3.4 summers.

\section{Why Does ENSO Modulate the Relationship Between the Mid-latitude Eurasian Circulation and HK Summer Rainfall?}

We showed that HK summer rainfall is significantly correlated to mid-latitude Eurasian circulation, but it is unclear why this relationship is different in the two phases of ENSO. In order to address this issue, Figure 10 shows the composite of the 200$\mathrm{hPa}$ circulation anomalies in positive and negative Niño-3.4 summers, as well as the difference in the interannual variance between the two phases. While the wind anomalies in the two phases are opposite in sign, the magnitudes of these anomalies in negative Niño 3.4 cases are generally stronger than the positive cases, including the anomalies over the Ural Mountains, the East Asian jet region, and the northwestern Pacific. In the negative Niño 3.4 summers, the weaker subtropical jet over Eurasia is associated with a stronger interannual variation of wind over the midlatitude Eurasia. This can be depicted by stronger interannual variances of zonal wind south of the Ural Mountains and south of Lake Baikal (shading in Figure 10A), and stronger interannual variances of meridional wind over Scandinavia, central Asia and northeastern Asia (shading in Figure 10B). In other words, the weaker subtropical jet in the negative Niño 3.4 summers may favor a stronger impact of the midlatitude circulation on the East Asian circulation related to the HK summer rainfall.

\section{Does Tropical Cyclone Activity Affect HK Summer Rainfall in the Two ENSO Phases?} As mentioned in the introduction, tropical cyclone (TC) activity is one of the factors contributing to $\mathrm{HK}$ summer rainfall. We have also correlated HK summer rainfall with summer TC track density in positive Niño-3.4 summers and negative Niño-3.4 summers separately. As shown in Figure 11A, more HK

\section{REFERENCES}

Chan, J. C. L., and Shi, J.-E. (1999). Prediction of the summer monsoon rainfall over South China. Int. J. Climatol. 19, 1255-1265. doi:10.1002/(sici)10970088(199909)19:11<1255::aid-joc430>3.0.co;2-k

Chan, J. C. L., and Zhou, W. (2005). PDO, ENSO and the early summer monsoon rainfall over south China. Geophys. Res. Lett. 32, L08810. doi:10.1029/ 2004GL022015

Chang, C.-P., Zhang, Y., and Li, T. (2000). Interannual and interdecadal variations of the East Asian summer monsoon and tropical Pacific SSTs. Part I: roles of the summer rainfall in positive Niño-3.4 summers is associated with fewer TCs over the Philippines and slightly more TCs passing across Taiwan and Fujian Province in southeastern China. However, it is not related to the TC track density along the South China coast. Conversely, more HK summer rainfall in negative Niño-3.4 summers is associated with more TCs making landfall over the South China coast (Figure 11B). Therefore, the HK summer rainfall anomaly in negative Niño-3.4 summers is also related to TC activity, while that in positive Niño-3.4 summers is not.

Overall, our results suggest that $\mathrm{HK}$ summer rainfall anomalies during the period 1979-2019 can be better predicted by the spring North Atlantic SST anomaly during negative Niño-3.4 summers. We also reveal a strong linkage between $\mathrm{HK}$ summer rainfall and circulation anomalies over the Urals and northeastern China in negative and positive Niño-3.4 summers. Because the persistence of height anomalies over these regions is related to the occurrence of Ural blocking and Okhotsk blocking, it is important to investigate the impact of blocking on rainfall in South China under different ENSO backgrounds in future.

\section{DATA AVAILABILITY STATEMENT}

The original contributions presented in the study are included in the article/Supplementary Material, further inquiries can be directed to the corresponding author.

\section{AUTHOR CONTRIBUTIONS}

Conceptualization: $\mathrm{H}-\mathrm{NC}$; methodology, and formal analysis: YL, and $\mathrm{H}-\mathrm{NC}$; original draft of the manuscript: $\mathrm{YL}$; review and editing of the manuscript: $\mathrm{H}-\mathrm{NC}$, and WZ; validation: YL, H-NC, and WZ.

\section{FUNDING}

HNC is supported by the National Natural Science Foundation of China (Grant No. 42088101, 41905050), and Guangdong Province Key Laboratory for Climate Change and Natural Disaster Studies (Grant No. 2020B1212060025). ZW is supported by the Center for Ocean Research in Hong Kong and Macau (CORE).

subtropical ridge. J. Climate. 13, 4310-4325. doi:10.1175/1520-0442(2000) $013<4310$ :iaivot>2.0.co;2

Chang, W. L., and Yeung, K. H. (2003). Seasonal forecasting for Hong Kong-a pilot study. Hong Kong Observatory, Technical Paper 104.

Chen, J., Wen, Z., Wu, R., Wang, X., He, C., and Chen, Z. (2017). An interdecadal change in the intensity of interannual variability in summer rainfall over southern China around early 1990s. Clim. Dyn. 48, 191-207. doi:10.1007/ s00382-016-3069-8

Chen, W., Feng, J., and Wu, R. (2013). Roles of ENSO and PDO in the link of the East Asian winter monsoon to the following summer monsoon. J. Climate. 26, 622-635. doi:10.1175/jcli-d-12-00021.1 
Chen, W., Graf, H.-F., and Huang, R. (2000). The interannual variability of East Asian winter monsoon and its relation to the summer monsoon. Adv. Atmos. Sci. 17, 48-60. doi:10.1007/s00376-000-0042-5

Chen, Y., and Zhai, P. (2014). Two types of typical circulation pattern for persistent extreme precipitation in Central-Eastern China. Q.J.R. Meteorol. Soc. 140, 1467-1478. doi:10.1002/qj.2231

Dai, L., Cheng, T. F., and Lu, M. (2020). Summer monsoon rainfall patterns and predictability over southeast China. Water Resour. Res. 56, e2019WR025515. doi:10.1029/2019WR025515

Ding, Y., and Chan, J. C. L. (2005). The East Asian summer monsoon: an overview. Meteorol. Atmos. Phys. 89, 117-142. doi:10.1007/s00703-005-0125-Z

Ding, Y. H., and Li, C. Y. (1999). Onset and evolution of the South China Sea monsoon and its interaction with the ocean. Beijing, China: China Meteorological Press, 423.

Fan, K., Xu, Z., and Tian, B. (2014). Has the intensity of the interannual variability in summer rainfall over South China remarkably increased?. Meteorol. Atmos. Phys. 124, 23-32. doi:10.1007/s00703-013-0301-5

Fan, Y., Fan, K., Xu, Z., and Li, S. (2018). ENSO-South China Sea summer monsoon interaction modulated by the Atlantic Multidecadal Oscillation. J. Climate 31, 3061-3076. doi:10.1175/JCLI-D-17-0448.1

Gong, D.-Y., and Ho, C.-H. (2003). Arctic oscillation signals in the East Asian summer monsoon. J. Geophys. Res. 108, 4066. doi:10.1029/ 2002JD002193

He, H., McGinnis, J., Song, Z., and Yanai, M. (1987). Onset of the asian monsoon in 1979 and the effect of the Tibetan plateau. Mon. Wea. Rev. 115, 1966-1995. doi:10.1175/1520-0493(1987)115<1966:ootasm>2.0.co;2

$\mathrm{He}, \mathrm{Z}$., and $\mathrm{Wu}, \mathrm{R}$. (2014). Indo-Pacific remote forcing in summer rainfall variability over the South China Sea. Clim. Dyn. 42, 2323-2337. doi:10. 1007/s00382-014-2123-7

Huang, R., and Wu, Y. (1989). The influence of ENSO on the summer climate change in China and its mechanism. Adv. Atmos. Sci. 6, 21-32. doi:10.1007/ BF02656915

Huang, W. R., and Chen, K. C. (2015). Trends in pre-summer frontal and diurnal rainfall activities during 1982-2012 over Taiwan and Southeast China: characteristics and possible causes. Int. J. Climatol 35, 2608-2619. doi:10. 1002/joc. 4159

Jiang, N., and Zhu, C. (2021). Seasonal forecast of south China sea summer monsoon onset disturbed by cold tongue La Niña in the past decade. Adv. Atmos. Sci. 38, 147-155. doi:10.1007/s00376-020-0090-y

Kajikawa, Y., and Wang, B. (2012). Interdecadal change of the South China Sea summer monsoon onset. J. Climate 25, 3207-3218. doi:10.1175/JCLI-D-1100207.1

Kim, S., and Ha, K.-J. (2021). Interannual and decadal covariabilities in East Asian and western North Pacific summer rainfall for 1979-2016. Clim. Dyn. 56, 1017-1033. doi:10.1007/s00382-020-05517-7

Lau, K.-M., Kim, K.-M., and Yang, S. (2000). Dynamical and boundary forcing characteristics of regional components of the Asian summer monsoon. J. Climate 13, 2461-2482. doi:10.1175/1520-0442(2000)013<2461:dabfco >2.0. $\mathrm{co} ; 2$

Lee, J.-Y., Wang, B., Ding, Q., Ha, K.-J., Ahn, J.-B., Kumar, A., et al. (2011). How predictable is the northern hemisphere summer upper-tropospheric circulation?. Clim. Dyn. 37, 1189-1203. doi:10.1007/s00382-010-0909-9

Leung, Y. K., Yeung, K. H., Ginn, E. W. L., and Leung, W. M. (2004). Climate change in Hong Kong. Hong Kong Observatory, Technical Paper 107.

Li, J., Zheng, F., Sun, C., Feng, J., and Wang, J. (2019a). Pathways of influence of the Northern Hemisphere mid-high latitudes on East Asian climate: a review. Adv. Atmos. Sci. 36, 902-921. doi:10.1007/s00376-019-8236-5

Li, Y., Yang, S., Deng, Y., and Zheng, B. (2020b). Signals of spring thermal contrast related to the interannual variations in the onset of the South China Sea summer monsoon. J. Clim. 33, 27-38. doi:10.1175/JCLI-D-190174.1

Li, R. C. Y., and Zhou, W. (2014). Interdecadal change in South China Sea tropical cyclone frequency in association with zonal sea surface temperature gradient. J. Clim. 27, 5468-5480. doi:10.1175/jcli-d-13-00744.1

Li, R. C. Y., Zhou, W., and Lee, T. C. (2015). Climatological characteristics and observed trends of tropical cyclone-induced rainfall and their influences on long-term rainfall variations in Hong Kong. Mon. Wea. Rev. 143, 2192-2206. doi:10.1175/MWR-D-14-00332.1
Li, S., Ji, L., Lin, W., and Ni, Y. (2001). The maintenance of the blocking over the ural mountains during the second meiyu period in the summer of 1998. Adv. Atmos. Sci. 18, 87-105. doi:10.1007/s00376-001-0006-4

Li, X., Zhou, W., Chen, D., Li, C., and Song, J. (2014). Water vapor transport and moisture budget over eastern China: remote forcing from the two types of $\mathrm{El}$ Niño. J. Clim. 27, 8778-8792. doi:10.1175/jcli-d-14-00049.1

Li, X., Zhou, W., Li, C., and Song, J. (2013). Comparison of the annual cycles of moisture supply over southwest and southeast China. J. Clim. 26, 10139-10158. doi:10.1175/JCLI-D-13-00057.1

Lin, A., Gu, D., Li, C., Zheng, B., and Liang, J. (2010). Relationship between the onset of the South China Sea summer monsoon and abnormal variations of frontal precipitation during the first rainy period in South China. Acta Sci. Nat. Univ. Sunyatseni. 49 (5), 136-143. [in Chinese].

Lin, Z. (2014). Intercomparison of the impacts of four summer teleconnections over Eurasia on East Asian rainfall. Adv. Atmos. Sci. 31, 1366-1376. doi:10. 1007/s00376-014-3171-y

Liu, B., Yan, Y., Zhu, C., Ma, S., and Li, J. (2020). Record-breaking Meiyu rainfall around the Yangtze River in 2020 regulated by the subseasonal phase transition of the north atlantic oscillation. Geophys. Res. Lett. 47. e2020GL090342, doi:10. 1029/2020GL090342

Liu, B., Zhu, C., Su, J., Ma, S., and Xu, K. (2019). Record-breaking northward shift of the western North Pacific subtropical high in July 2018. J. Meteor. Soc. Japan. 97, 913-925. doi:10.2151/jmsj.2019-047

Liu, B., Zhu, C., Yuan, Y., and Xu, K. (2016). Two types of interannual variability of South China Sea summer monsoon onset related to the SST anomalies before and after 1993/94. J. Clim. 29, 6957-6971. doi:10.1175/JCLI-D-16-0065.1

Liu, K. S., and Chan, J. C. L. (2019). Interdecadal variation of frequencies of tropical cyclones, intense typhoons and their ratio over the western North Pacific. Int. J. Climatol. 40, 3954-3970. doi:10.1002/joc.6438

Ninomiya, K., and Shibagaki, Y. (2007). Multi-scale features of the Meiyu-Baiu front and associated precipitation systems. Jmsj. 85B, 103-122. doi:10.2151/ jmsj.85b.103

Ogi, M., Tachibana, Y., and Yamazaki, K. (2004). The connectivity of the winter North Atlantic oscillation (NAO) and the summer Okhotsk high. J. Meteor. Soc. Japan. 82, 905-913. doi:10.2151/jmsj.2004.905

Si, D., and Ding, Y. (2016). Oceanic forcings of the interdecadal variability in East Asian summer rainfall. J. Clim. 29, 7633-7649. doi:10.1175/JCLI-D-15-0792.1

Sung, M.-K., Kwon, W.-T., Baek, H.-J., Boo, K.-O., Lim, G.-H., and Kug, J.-S. (2006). A possible impact of the North Atlantic oscillation on the east Asian summer monsoon precipitation. Geophys. Res. Lett. 33, L21713. doi:10.1029/ 2006GL027253

Takaya, K., and Nakamura, H. (2001). A formulation of a phase-independent wave-activity flux for stationary and migratory quasigeostrophic eddies on a zonally varying basic flow. J. Atmos. Sci. 58, 608-627. doi:10.1175/15200469(2001)058<0608:afoapi>2.0.co;2

Tao, S., and Chen, L. (1987). "A review of recent research on the East Asian summer monsoon in China," in Monsoon meteorology. Editors C.-P. Chang and T. N. Krishnamurti (Oxford, United Kigdom: Oxford University Press), 60-92.

Wang, B., Li, J., and He, Q. (2017). Variable and robust East Asian monsoon rainfall response to El Niño over the past 60 years (1957-2016). Adv. Atmos. Sci. 34, 1235-1248. doi:10.1007/s00376-017-7016-3

Wang, B., LinHoZhang, Y., and Zhang, M.-M. (2004). Definition of south China sea monsoon onset and commencement of the east Asia summer monsoon*. J. Clim. 17, 699-710. doi:10.1175/2932.1

Wang, X., Wang, D., Zhou, W., and Li, C. (2012). Interdecadal modulation of the influence of La Niña events on mei-yu rainfall over the Yangtze River valley. Adv. Atmos. Sci. 29, 157-168. doi:10.1007/s00376-011-1021-8

Wang, Y. (1992). Effects of blocking anticyclones in Eurasia in the rainy season (Meiyu/Baiu season). J. Meteor. Soc. Japan. 70, 929-951. doi:10.2151/jmsj1965. 70.5_929

Wang, Y., and Yasunari, T. (1994). A diagnostic analysis of the wave train propagating from high-latitudes to low-latitudes in early summer. J. Meteor. Soc. Japan. 72, 269-279. doi:10.2151/jmsj1965.72.2_269

Wang, Z., Yang, S., Lau, N.-C., and Duan, A. (2018). Teleconnection between summer NAO and East China rainfall variations: a bridge effect of the Tibetan Plateau. J. Climate 31, 6433-6444. doi:10.1175/JCLI-D-17-0413.1

Watanabe, M. (2004). Asian jet waveguide and a downstream extension of the North Atlantic Oscillation. J. Clim. 17, 4674-4691. doi:10.1175/JCLI-3228.1 
Wei, W., Zhang, R., and Wen, M. (2015). Interannual variation of the South Asian high and its relation with Indian and East Asian summer monsoon rainfall. J. Clim. 28, 2623-2634. doi:10.1175/JCLI-D-14-00454.1

Wu, G., Duan, A., Liu, Y., Yan, J., Liu, B., Ren, S., et al. (2013). Recent advances in the study on the dynamics of the Asian summer monsoon onset. Chin. J. Atmos. Sci. 37, 211-228 [in Chinese]. doi:10.3878/j.issn.1006-9895.2012.12312

Wu, M. C., and Chan, J. C. L. (2005). Observational relationships between summer and winter monsoons over East Asia. Part II: results. Int. J. Climatol. 25, 453-468. doi:10.1002/joc.1153

Wu, R., Hu, Z.-Z., and Kirtman, B. P. (2003). Evolution of ENSO-related rainfall anomalies in East Asia. J. Climate. 16, 3742-3758. doi:10.1175/1520-0442(2003) 016<3742:eoerai $>2.0$. co; 2

Wu, R., Wen, Z., Yang, S., and Li, Y. (2010). An interdecadal change in southern China summer rainfall around 1992/93. J. Clim. 23, 2389-2403. doi:10.1175/2009jcli3336.1

Wu, Z., Wang, B., Li, J., and Jin, F.-F. (2009). An empirical seasonal prediction model of the East Asian summer monsoon using ENSO and NAO. J. Geophys. Res. 114, D18120. doi:10.1029/2009JD011733

Xing, W., Wang, B., and Yim, S.-Y. (2016). Peak-summer East Asian rainfall predictability and prediction part I: southeast Asia. Clim. Dyn. 47, 1-13. doi:10. 1007/s00382-014-2385-0

Yim, S.-Y., Wang, B., and Xing, W. (2014). Prediction of early summer rainfall over South China by a physical-empirical model. Clim. Dyn. 43, 1883-1891. doi:10. 1007/s00382-013-2014-3

Yuan, F., Chen, W., and Zhou, W. (2012). Analysis of the role played by circulation in the persistent precipitation over South China in June 2010. Adv. Atmos. Sci. 29, 769-781. doi:10.1007/s00376-012-2018-7
Zhang, R., Sumi, A., and Kimoto, M. (1999). A diagnostic study of the impact of El Niño on the precipitation in China. Adv. Atmos. Sci. 16, 229-241. doi:10.1007/ bf02973084

Zheng, B., Liang, J., Lin, A., Li, C., and Gu, D. (2006). Frontal rain and summer monsoon rain during pre-rainy season in South China. Part I: determination of the division dates. Chin. J. Atmos. Sci. 30, 1207-1216. doi:10.3878/j.issn.10069895.2006.06.15

Zhou, W., and Chan, J. C. L. (2007). ENSO and the South China Sea summer monsoon onset. Int. J. Climatol. 27, 157-167. doi:10.1002/joc.1380

Zhou, W., Chan, J. C. L., and Li, C. (2005). South China Sea summer monsoon onset in relation to the off-equatorial ITCZ. Adv. Atmos. Sci. 22, 665-676. doi:10.1007/BF02918710

Zhu, Z., and Li, T. (2017). Empirical prediction of the onset dates of South China Sea summer monsoon. Clim. Dyn. 48, 1633-1645. doi:10.1007/s00382-016-3164-x

Conflict of Interest: The authors declare that the research was conducted in the absence of any commercial or financial relationships that could be construed as a potential conflict of interest.

Copyright (C) $2021 \mathrm{Li}$, Cheung and Zhou. This is an open-access article distributed under the terms of the Creative Commons Attribution License (CC BY). The use, distribution or reproduction in other forums is permitted, provided the original author(s) and the copyright owner(s) are credited and that the original publication in this journal is cited, in accordance with accepted academic practice. No use, distribution or reproduction is permitted which does not comply with these terms. 